\title{
Genetic Aspects of Selective Immunoglobulin A Deficiency*
}

\author{
F. J. GRUNDBACHER \\ From the Department of Genetics, Medical College of Virginia, Richmond, USA
}

Selective deficiency of immunoglobulin A (IgA) occurs with a frequency of about one in 500 individuals (Hobbs, 1968). Many cases occur sporadically but an accumulation of cases was observed in some families for which genetic factors were postulated. Autosomal dominant, autosomal recessive, autosomal recessive with incomplete penetrance, obscure inheritance, polygenic phenomena, and perhaps a genetically determined defect, are examples proposed in the literature to account for the familial cases of IgA deficiency (Goldberg, Barnett, and Fudenberg, 1968; Hobbs, 1968; Stocker, Ammann, and Rossi, 1968; Crabbé and Heremans, 1969; Bach, Pillay, and Kark, 1971; Douglas, Goldberg, and Fudenberg, 1971; Tomkin, Mawhinney, and Nevin, 1971). Clearly, disagreement or uncertainty prevails concerning the basis of $\operatorname{IgA}$ deficiency.

Results of a study of 2 families with IgA-deficient members are presented in this report. Based on these results and those previously published in the literature an interpretation for IgA deficiency is proposed which can account for all cases of selective IgA deficiency.

\section{Materials and Methods}

A population survey was conducted among individuals of Richmond, Virginia, and the surrounding counties for determination of the causes of variation in levels of immunoglobulins and isoantibodies. Two families with IgA-deficient members were found among 623 persons belonging to 87 families. The first was a large Black family containing some Indian admixture (presumably Mattaponi Indian) with 9 children; the second was a White family with 3 children. Uncles, aunts, and first cousins of the deficient individuals were also studied. Blood group antigens did not indicate any illegitimacy in these families. The age of the children ranged from 4 to 14 years.

\footnotetext{
Received 3 March 1972.

* This work was supported in part by United States Public Health Service research grant AI 08736 from the National Institute of Allergy and Infectious Diseases.
}

Immunoglobulins IgG, IgM, IgA, and IgD were quantitated by the radial diffusion techniquet as previously described (Grundbacher and Shreffler, 1970a). The serum of the IgA-deficient individuals was retested with low level anti-IgA agar plates, and the serum without any IgA was also tested in Ouchterlony double diffusions against anti-IgA.

\section{Results}

The mean serum IgA concentration was $143.9 \pm$ $4.8 \mathrm{mg} / 100 \mathrm{ml}$ in Whites (mean age 21.0 years) and $169.1 \pm 4.0$ in Blacks (mean age 18.3 years). The pedigrees of the families with IgA-deficient mem bers are given in Fig. 1. No trace of IgA was des tected in the serum of the deficient 10-year-old bo (D.L.) in family 1. His IgM was within the range of the other sibs but his IgG level was much higher than in any of his sibs and his parents. Thus, the absence of IgA in this boy seems to be compensated for by an increased level of IgG; his total absolute immunoglobulin level $(\operatorname{IgG}+\operatorname{IgM}+\operatorname{IgD})$ is higher than in any of his sibs. The IgD level was within the range of the other children, indicating that absence of IgA did not influence the IgD level. The immunoglobulin levels in all the uncles, aunts, and first cousins of the deficient boy were within the normal range.

The 2 IgA-deficient boys of family 2 (Fig. 1) were 8 and 7 years old. The fact that they are younger than their normal brother cannot account for the difference in IgA levels because at their age an average of about $90 \mathrm{mg} / 100 \mathrm{ml}$ of serum is expected (Grundbacher and Shreffler, 1970b). The low IgA level in the sera of these boys also seems to have been compensated for with IgG, although the pattern is not as distinct as in family 1 .

No IgA was detected in the saliva of the 3 IgAdeficient boys, but none had any unusual problems with infections nor with atopic hypersensitivities.

† Using commercially produced antibody agar plates from Melpar, Springfield, Virginia. 
FAMILY I

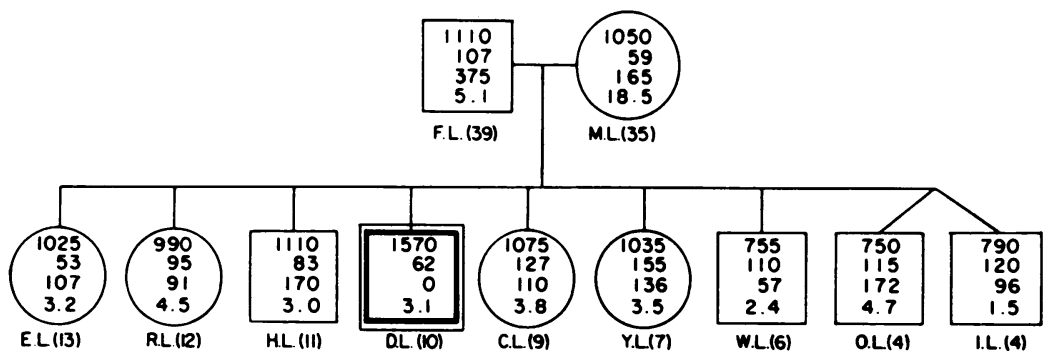

FAMILY 2

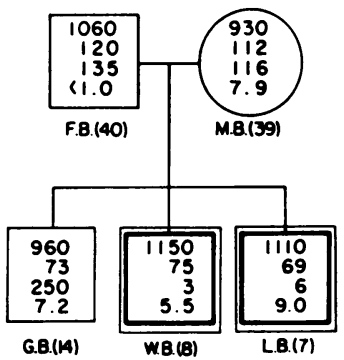

Fig. 1. Pedigree of families with IgA-deficient boys. The uppermost' number within squares and circles gives the IgG in $\mathrm{mg} / 100 \mathrm{ml}$ followed by IgM, IgA, and IgD in that order. Age of the individual is given in parentheses beside the initials. The squares of IgA deficient boys are accentuated.

Also all the relatives appeared normal. The finding of $3 \mathrm{IgA}$-deficient boys and no IgA-deficient girl is presumed to have occurred by chance because IgA deficiency is known to occur also in girls. However, sex differences for other immunologic properties have been recognized (Grundbacher, 1972).

\section{Discussion}

The data presented have shown that in individuals with serum IgA deficiency the IgG level is elevated compared with non-deficient sibs, but IgM and IgD levels are the same as in normal sibs. The IgA and IgG levels therefore seem to be interdependent, while IgM and IgD levels are relatively independent of IgA levels. The present finding of 3 IgAdeficient boys with normal health illustrates again that the deficiency may have no detrimental effects, although atopy and respiratory infections may occur more frequently in IgA deficiency than in normal individuals (Collins-Williams et al, 1972).

The finding of 2 brothers with very low IgA levels provides some evidence for a contribution of genetic factors to the development of IgA deficiency. Family 1, however, comprising one IgA-deficient boy, 8 normal sibs, normal parents, normal uncles, aunts, and first cousins suggest that IgA deficiency is not conditioned by a single gene. For a dominant mode of inheritance a new mutation would have to be postulated which appears unlikely.

Among the reports on IgA deficiency in the literature, an autosomal dominant mode was suggested for 2 families but for one of these (Stocker et al, 1968) a mutation has to be postulated because the grandparents had normal immunoglobulin levels. In the other family (Tomkin et al, 1971) the grandparents could not be tested. Crabbé and Heremans (1969) suggested an autosomal recessive mode of inheritance because of the relatively high incidence and because of the frequent absence of other im- mune defects among the relatives of IgA-deficient individuals. Hobbs (1968) observed IgA deficiency in 7 out of 15 relatives of IgA-deficient persons but the degree of deficiency varied widely. He suggested a genetic basis for the defect but concluded that the mode of inheritance is obscure. Natvig et al (1971) studied 11 families with IgA-deficient members and found no family members other than the proband except for a mother and her daughter.

Goldberg et al (1968) investigated a large family but found only one deficient relative in addition to the IgA-deficient proband. Absence of $\operatorname{IgA}$ was detected by Bach et al (1971) in a patient with systemic lupus erythematosus. Five of 14 relatives of the patient had low levels to absent IgA. Hanson (1968) found in 42 relatives of 12 IgA-deficient individuals only one brother lacking IgA.

The present data combined with the reports in the literature permit the following generalizations concerning the incidence of IgA deficiency.

(1) The defect shows a familial tendency in some families but many IgA-deficient individuals have normal relatives only.

(2) Selective absence of $\operatorname{IgA}$ and very low levels may be found among members of the same family (Stocker et al, 1968; Bach et al, 1971; Douglas et al, 1971) indicating that the basis of the defect is similar for complete absence and very low IgA levels.

(3) The incidence is increased in chromosomal abnormalities such as partial deletion of the long or the short arm of chromosome 18 (Masterson and Law, 1969; Fischer et al, 1970; Jansch, May, and LaMarche, 1970; Stewart et al, 1970), ring formation 18 (Feingold et al, 1968; Peterson and Good, 1968; Murken, Salzer, and Kunze, 1970), trisomy 18 (Hecht, 1969), and heritable fragile site on chromosome 16 (Magenis, Hecht, and Lovrien, 1970).

(4) The frequency of IgA deficiency is much 


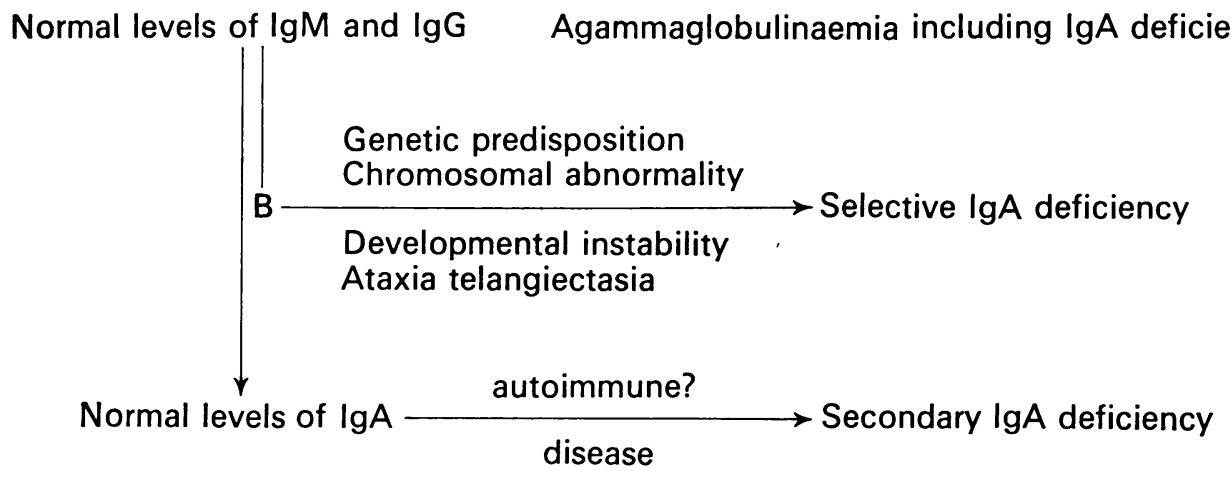

FIG. 2. Schematic illustration of the causes of IgA deficiencies. After the development of normal IgM and IgG, a disturbance at B caused by either of the 4 items listed or a combination thereof may lead to selective IgA deficiency.

higher in patients with ataxia telangiectasia than in normal individuals (Eidelman and Davis, 1968; Peterson and Good, 1968).

The frequent occurrence of sporadic cases and the lack of any uniform pattern for the familial cases indicate that no simple mode of inheritance can account for IgA deficiency. This conclusion is further supported by the observation that complete absence of IgA and low levels occur among members of the same family, that is, deficiency may show different degrees. However, IgA deficiency is comcompatible with a polygenic concept where a certain predisposition to the defect is inherited and developmental factors are also of importance. With a certain inherited predisposition the defect may or may not develop depending on the environmental or developmental circumstances, and the deficiency may be partial or complete. The contribution of genetic factors is indicated by the accumulation of the defect in some families, and the high incidence of IgA deficiency in chromosomal abnormalities suggests a contribution of developmental factors. Imbalanced development is a general consequence of chromosomal abnormalities. The hypothesis for primary absence of IgA deficiency is illustrated in Fig. 2.

The concept of polygenic inheritance of a predisposition to the defect may account for familial and sporadic cases and also is compatible with the observation of complete and partial IgA deficiency occurring among members of the same family. The polygenic concept is in good agreement with the postulate of Natvig et al (1971) stating that a regulatory rather than a structural gene defect is responsible for IgA deficiency. With polygenic inheritance of a predisposition to the defect a few families are expected to show a pattern which may also be compatible with an autosomal dominant mode of inheri- tance. Such families, however, represent only a very small fraction of all the cases of IgA deficiency.

In several respects the IgA deficiency shows similarities to the aetiology of cleft lip and palate for which originally autosomal dominant, autosomal recessive and sex-linked modes of inheritance were postulated but where now a polygenic predisposition to the defect has been accepted as the most likely genetic mechanism to explain the occurrence of a familial tendency (Fraser, 1970). In chromosomal abnormalities the incidence of cleft lip and palate is also increased. Thus, developmental imbalance 0 . resulting from chromosomal abnormalities appears to increase the incidence of both IgA deficiency and cleft lip and palate.

\section{Summary}

A boy was found with complete absence of IgA who had 8 normal sibs, normal parents, uncles, aunts, and first cousins. In a second family, 2 out of 3 boys had very low levels of IgA and normal relatives. The IgG level was higher in the IgAdeficient boys than in normal sibs but the $\operatorname{IgM}$ and IgD levels were not influenced. These families and evidence published in the literature indicate that a predisposition to IgA deficiency is inherited by polygenic factors, but that developmental factors also may cause the defect as evidenced by IgA deficiency in various chromosomal abnormalities.

\section{REFERENCES}

Bach, G. L., Pillay, V. K. G., and Kark, R. M. (1971). Immunoglobulin (IgA) deficiency in systemic lupus erythrematosus. Acta Rheumatologica Scandinavica, 17, 63-71.

Collins-Williams, C., Kokubu, H. L., Lamenza, C., Nizami, R., Chiu, A. W., Lewis-McKinley, C., Comerford, T. A., and Varga, E. A. (1972). Incidence of isolated deficiency of IgA in the serum of Canadian children. Annals of Allergy, 30, 11-23.

Crabbé, P. A. and Heremans, J. F. (1969). The genetics of IgA deficiency. Protides of the Biological Fluids, 17, 91-97. 
Douglas, S. D., Goldberg, L. S., and Fudenberg, H. H. (1971). Familial selective deficiency of IgA. Fournal of Pediatrics, 78, 873-875.

Eidelman, S. and Davis, S. D. (1968). Immunoglobulin content of intestinal mucosal plasma-cells in ataxia telangiectasia. Lancet, 1 , 884-886.

Feingold, M., Schwartz, R. S., Atkins, L., Anderson, R., Bartsocas, C. S., Page, D. L., and Littlefield, J. W. (1969). IgA deficiency associated with partial deletion of chromosome 18. American fournal of Diseases of Children, 117, 129-136.

Fischer, P., Golob, E., Friedrich, F., Kunze-Mühl, E., Doleschel, W., and Aichmar, H. (1970). Autosomal deletion syndrome 46, XX, $18 \mathrm{p}-:$ a new case report with absence of IgA in serum. Fournal of Medical Genetics, 7, 91-98.

Fraser, F. C. (1970). The genetics of cleft lip and cleft palate. American fournal of Human Genetics, 22, 336-352.

Goldberg, L. S., Barnett, E. V., and Fudenberg, H. H. (1968), Selective absence of IgA: a family study. Fournal of Laboratory and Clinical Medicine, 72, 204-212.

Grundbacher, F. J. (1972). Human X-chromosome carries quantitative genes for immunoglobulin M levels. Science, 176, 311-312.

Grundbacher, F. J. and Shreffler, D. C. (1970a). Effects of secretor, blood and serum groups on isoantibody and immunoglobulin levels. American fournal of Human Genetics, 22, 194-202.

Grundbacher, F. J. and Shreffler, D. C. (1970b). Changes in human serum immunoglobulin levels with age and sex. Zeitschrift für Immunitätsforschung, 141, 20-26.

Hanson, L. A. (1968). Aspects of the absence of the IgA system. In: Immunologic deficiency disease in man. Birth Defects: Original Article Series, IV, 1, 292-297. National FoundationMarch of Dimes, New York.
Hecht, F. (1969). IgA and partial deletions of chromosome 18. Lancet, 1, 100-101.

Hobbs, J. R. (1968). Immune imbalance in dysgammaglobulinaemia type IV. Lancet, 1, 110-114.

Jansch, M. E., May, J. B., and LaMarche, P. H. (1970). 18p-/Gqmosaicism in a girl with absent IgA. Rhode Island Medical fournal, 53, 623-625.

Magenis, R. E., Hecht, F., and Lovrien, E. W. (1970). Heritable fragile site on chromosome 16: probable localization of haptoglobin locus in man. Science, 170, 85-86.

Masterson, J. G. and Law, E. M. (1969). IgA and partial deletions of chromosome 18. Irish fournal of Medical Science, 7th series, 2, 265-267.

Murken, J. D., Salzer, G., and Kunze, D. (1970). Ringchromosom Number 18 und fehlendes IgA bei einem 6 jährigen Mädchen (46, $\mathrm{XX}, 18 \mathrm{r}$ ). Zeitschrift für Kinderheilkunde, 109, 1-10.

Natvig, J. B., Harboe, M., Fausa, O., and Tveit, A. (1971). Family studies in individuals with selective absence of $\gamma \mathrm{A}$-globulin. Clinical and Experimental Immunology, 8, 229-236.

Peterson, R. D. A. and Good, R. A. (1968). Ataxia-telangiectasia. In: Immunological deficiency diseases in man. Birth Defects: Original Article Series, IV, 1, 370-377. National FoundationMarch of Dimes, New York.

Stewart, J. M., Go, S., Ellis, E., and Robinson, A. (1970). Absent IgA and deletions of chromosome 18. Fournal of Medical Genetics, 7, 11-19.

Stocker, F., Ammann, P., and Rossi, E. (1968). Selective $\gamma$-Aglobulin deficiency, with dominant autosomal inheritance in a Swiss family. Archives of Disease in Childhood, 43, 585-588.

Tomkin, G. H., Mawhinney, H., and Nevin, N. C. (1971). Isolated absence of IgA with autosomal dominant inheritance. Lancet, 2 , 124-125. 